\title{
Characterization of fimbrial subunits from Bordetella species
}

\author{
Frits R. Mooi, ${ }^{1}$ Han G. J. van der Heide, ${ }^{1}$ Anja R. ter Avest, ${ }^{1}$ \\ Karen G. Welinder, ${ }^{2}$ Ian Livey, ${ }^{3}$ Ben A. M. van der Zeijst ${ }^{4}$ \\ and Wim Gaastra ${ }^{4}$
}

'Laboratory for Bacteriology, Rijksinstituut voor Volksgezondheid en Milieuhygiene, PO Box 1, 3720 BA Bilthoven, The Netherlands; ${ }^{2}$ Institute of Biochemical Genetics, University of Copenhagen, DK-1353 Copenhagen K, Denmark; ${ }^{3} P H L S$ Centre for Applied Microbiology and Research, Porton Down, Salisbury, Wiltshire SP4 OJG, England; ${ }^{4}$ Department of Infectious Diseases, Section Bacteriology, Veterinary Faculty, State University, Yalelaan 1, 3584 CL Utrecht, The Netherlands

(Received February 24, 1987; accepted March 1,1987)

Mooi, F. R. (Laboratory for Bacteriology, RIVM, PO Box 1, 3720 BA Bilthoven, The Netherlands), H. G. J. van der Heide, A. R. ter Avest, K. G. Welinder, I. Livey, B. A. M. van der Zeijst and W. Gaastra. Characterization of fimbrial subunits from Bordetella species. Microbial Pathogenesis 1987; 2: 473-484.

Using antisera raised against serotype 2 and 3 fimbrial subunits from Bordetella pertussis, serologically related polypeptides were detected in Bordetella bronchiseptica, Bordetella parapertussis and Bordetella avium strains. The two $B$. pertussis fimbrial subunits, and three of the serologically related $B$. bronchiseptica polypeptides, were shown to be very similar in amino acid composition and $\mathbf{N}$-terminal amino acid sequence. Homology was observed between the $\mathrm{N}$-termini of these polypeptides, and fimbrial subunits from Escherichia coli, Haemophilus influenzae and Proteus mirabilis. A synthetic oligonucleotide probe, derived from the $\mathrm{N}$-terminal sequence of the $B$. pertussis serotype 2 fimbrial subunit, was used to identify fimbrial genes in genomic Southern blots. The results suggested the presence of multiple fimbrial subunit genes in $B$. pertussis, $B$. bronchiseptica and $B$. parapertussis. The DNA probe was used to clone one of the three tentative fimbrial subunit genes detected in $B$. pertussis.

Key words: Bordetella; fimbriae; serology; antigenic variation; fimbrial genes; cloning.

\section{Introduction}

All known members of the genus Bordetella are pathogenic microorganisms involved in infections of the respiratory tract. A first and essential step in the pathogenesis of these infections is the adherence to host epithelial cells. In many cases studied so far it has been shown that adherence is mediated by extracellular proteins called fimbriae or pili (see ref. 1 for a recent review). In view of their role in the establishment of disease, it is not surprising that studies, using experimental animal models, have shown that fimbriae are potentially important vaccine components. ${ }^{2,3}$ However, the efficacy of a fimbrial vaccine is often limited, due to the occurrence of different antigenic types of fimbriae within a single species. ${ }^{4}$ Immunization with a particular fimbrial serotype does not always confer protective immunity against infection by a strain carrying a 
different fimbrial serotype. Antigenic variation of fimbriae has also been observed in Bordetella. B. pertussis has been shown to produce two types of fimbriae, previously designated serotype 2 and 3 agglutinogens. ${ }^{5}$ The serotype 2 and 3 fimbriae are composed of subunits with molecular weights of 22500 and 22000 , respectively. ${ }^{6}$ Strains of $B$. pertussis may produce both types of fimbriae, or only a single type. Three serologically cross-reactive fimbrial subunits, with molecular weights of 21000,22000 and 24000 , have been described in $B$. bronchiseptica strains. The occurrence of multiple fimbriae in Bordetel/a species raises a number of questions relevant for the construction of a vaccine containing fimbriae. First, does the structural heterogeneity also imply functional heterogeneity, i.e. do different fimbriae recognize different receptors? Second, is it possible to locate conserved regions within the fimbriae, preferably the receptor binding domain, that confer protective immunity against strains with different antigenic types of fimbriae? In a first attempt to answer these questions, we have studied the structure and relatedness of fimbrial subunits produced by various Bordetella species. Furthermore, we have isolated one of the fimbrial subunit genes detected in $B$. pertussis by molecular cloning.

\section{Results}

\section{Serological relatedness of Bordetella fimbrial subunits}

Fimbriae produced by related bacterial species may show extensive serological crossreactivity. ${ }^{4}$ Thus antisera raised against fimbriae derived from a particular strain can be used to search for the presence of fimbriae in related strains. We preferred to use immunoblotting for this screening because this technique gives information on serological relatedness and molecular weights of individual polypeptides. The molecular weight of the polypeptides detected is relevant because fimbrial subunits generally have a molecular weight falling in the range 14000 to $30000 .{ }^{1}$ Sera raised aginst native fimbriae gave very weak reactions on immunoblots (not shown). Apparently, antibodies elicited by native fimbriae are mainly directed against conformational determinants, not present on SDS-denaturated fimbrial subunits. To circumvent this problem antisera were raised against SDS-denaturated fimbrial subunits (see 'Materials and methods').

Because the serotype 2 and 3 fimbriae produced by $B$. pertussis are well characterized, ${ }^{5,6}$ we used antisera against their subunits in our study (Fig. 1). The molecular weights we observed for the serotype 2 and 3 fimbrial subunits (24500 and 24000 respectively) were somewhat larger than those published by Irons et al. ${ }^{6}$ (22500 and 22000 respectively). These differences are probably due to different electrophoresis conditions. The serotype 2 antiserum gave a strong reaction with the serotype 2 fimbrial subunit, but only a weak reaction with the serotype 3 fimbrial subunit. The serotype 3 antiserum also reacted with both fimbrial subunits, the reaction with the serotype 3 subunit being much stronger. In addition to the serotype 2 and 3 fimbrial subunits, these two antisera recognized a number of other polypeptides in B. pertussis strains. With the serotype 2 antiserum three additional polypeptides, with molecular weights of 21000,20000 and 14000 , were detected. These polypeptides were always found associated with strains producing serotype 2 fimbrial subunits, and were also detected in purified serotype 2 fimbrial preparations. The intensity of these bands increased upon storage of the preparations, suggesting that they represent degradation products of the serotype 2 fimbrial subunit. In addition to the two $B$. pertussis fimbrial subunits, the serotype 3 antiserum recognized a polypeptide with a molecular weight of 35000 . Polypeptides with similar molecular weights were also detected in $B$. bronchiseptica strains, but not in $B$. parapertussis and $B$. avium strains. Furthermore, 


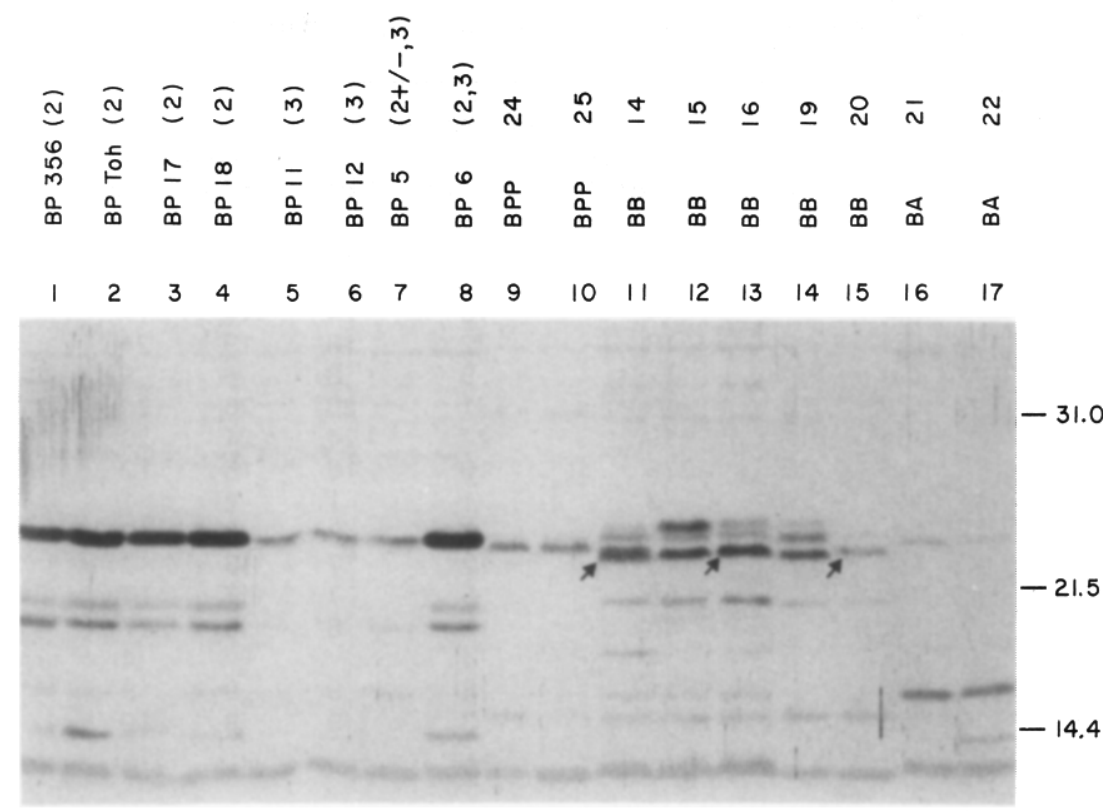

ST2 serum

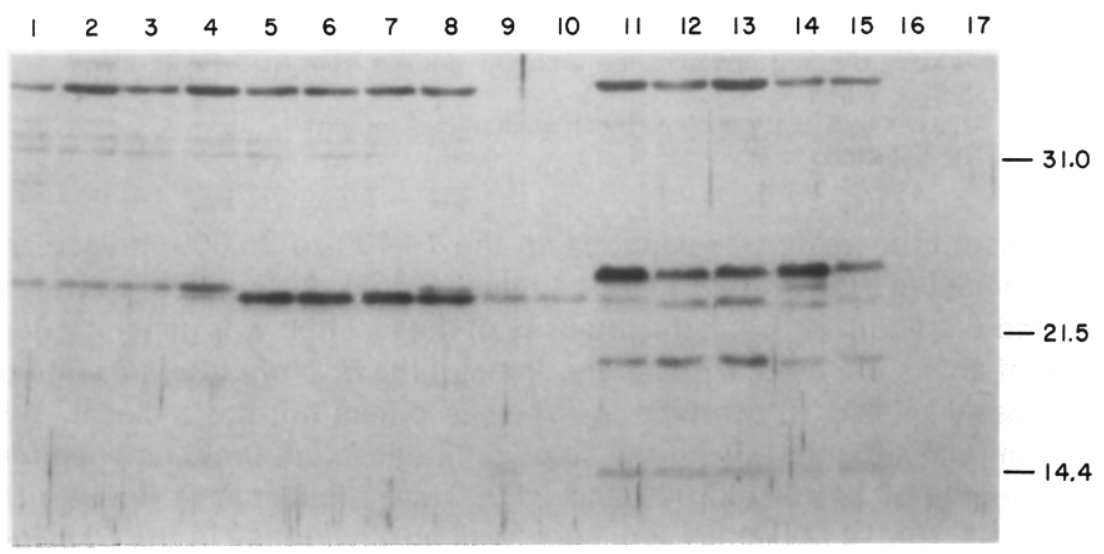

ST 3 serum

Fig. 1. Immunoblots of Bordetella strains, using antisera directed against serotype 2 (st2), and serotype 3 (st3) fimbrial subunits from $B$. pertussis. Total cell-lysates, containing $1 \mu \mathrm{g}$ of protein, were applied to the lanes. The numbers above the lanes, between parentheses, indicate the serotype of fimbriae produced by the $B$. pertussis strains as determined by the slide agglutination test. Arrows designate $B$. bronchiseptica polypeptides isolated. The numbers to the right of the immunoblot indicate the molecular weights $\left(\times 10^{-3}\right)$ of marker proteins. $\mathrm{BP}=B$. pertussis; $\mathrm{BPP}=B$. parapertussis; $\mathrm{BB}=B$. bronchiseptica; $\mathrm{BA}=\mathrm{B}$. avium; Toh $=$ Tohamal.

the polypeptide was not detected in preparations containing purified $B$. pertussis fimbriae (not shown). In view of its high molecular weight it seems unlikely that the 35000 Da polypeptide represents a fimbrial subunit.

The two antisera were also used to determine whether other Bordetella species produced polypeptides serologically related to $B$. pertussis fimbrial subunits (Fig. 1). Only one cross-reacting polypeptide $\left(\mathrm{M}_{\mathrm{r}}=24000\right)$ was observed in the two $B$. parapertussis strains tested. No significant difference was observed between the two antisera tested with respect to the intensity of the reaction with this polypeptide. With 
Table 1 Amino acid composition of fimbrial subunits

\begin{tabular}{|c|c|c|c|c|c|}
\hline \multirow[b]{3}{*}{ Amino acid } & \multicolumn{5}{|c|}{ Residues per subunit ${ }^{a}$} \\
\hline & \multicolumn{2}{|c|}{ B. pertussis } & \multicolumn{3}{|c|}{ B. bronchiseptica } \\
\hline & Tohamal(st2) & BP11(st3) & BB14 & BB16 & BB20 \\
\hline Asx & 25 & 25 & 22 & 22 & 20 \\
\hline Thr & 25 & 15 & 17 & 17 & 12 \\
\hline Ser & 14 & 18 & 14 & 14 & 17 \\
\hline Glx & 18 & 22 & 18 & 19 & 24 \\
\hline Pro & 12 & 9 & 8 & 8 & 9 \\
\hline Gly & 19 & 31 & 26 & 26 & $(26)^{b}$ \\
\hline Ala & 19 & 27 & 24 & 24 & 23 \\
\hline Val & 15 & 10 & 16 & 15 & 12 \\
\hline Met & 3 & 1 & 1 & 2 & 1 \\
\hline Ile & 11 & 7 & 8 & 8 & 8 \\
\hline Leu & 10 & 12 & 17 & 16 & 18 \\
\hline Tyr & 8 & 6 & 7 & 7 & 4 \\
\hline Phe & 5 & 2 & 8 & 8 & 7 \\
\hline His & 4 & 4 & $-c$ & $-c$ & 4 \\
\hline Lys & 14 & 18 & 9 & 9 & 9 \\
\hline Arg & 8 & 3 & 9 & 9 & 10 \\
\hline glucose-amine & $\mathrm{ND}^{d}$ & $\mathrm{ND}^{\alpha}$ & $2-4$ & $2-4$ & $\mathrm{ND}^{d}$ \\
\hline
\end{tabular}

${ }^{2}$ Based on the following molecular weights: 24500 for Tohamal serotype 2 (st2) subunit; 24000 for BP11 serotype 3 (st3) subunit; 23500 for the $B$. bronchiseptica subunits.

${ }^{b}$ Assumed value; the preparation contained very high amounts of Gly, presumably due to contamination with Gly derived from SDS-PAGE electrophoresis buffer,

'This $\mathrm{His}$ peak was obscured by an unidentified impurity.

${ }^{d}$ Not detected.

the two antisera four to six polypeptides, in the 14400 to 26000 molecular weight range, were detected in $B$. bronchiseptica strains (Fig. 1). Although most polypeptides were detected with both antisera, the intensity of the reaction was generally dependent on the type of antiserum used. Apparently, some of the $B$. bronchiseptica polypeptides are more closely related to serotype 2 , whereas others are more closely related to serotype 3 fimbrial subunits. Using the serotype 2 antiserum three polypeptides, with molecular weights of 14400,17000 and 24000 were detected in the two $B$. avium strains analyzed. The 14400 Da polypeptide was observed only in the $B$. avium strain BA22. The polypeptides were not detected using the serotype 3 antiserum.

\section{Amino acid analyses of $\mathrm{B}$. pertussis and $\mathrm{B}$. bronchiseptica fimbrial subunits}

$B$. pertussis serotype 2 and 3 fimbrial subunits were purified, and their amino acid composition (Table 1) and $\mathrm{N}$-terminal amino acid sequence (Table 2) was determined. Furthermore, three of the $B$. bronchiseptica polypeptides, detected with the serotype 2 and serotype 3 antisera, were also isolated and subjected to total and $\mathrm{N}$-terminal amino acid analyses (Tables 1 and 2). The latter polypeptides have been indicated by arrows in Fig. 1. The total analyses revealed that all five Bordetella polypeptides have very similar amino acid compositions. Furthermore, the amino acid composition of the serotype 2 fimbrial subunit, as determined in this study, is very similar to the composition published by Zhang et al. ${ }^{8}$ Two to four glucose-amine molecules per subunit were detected in the preparations containing polypeptides derived from the $B$. bronchiseptica strains BB14 and BB16. It remains to be determined whether these amino-sugars are covalently attached to the fimbrial subunits, or derived from the cell envelope. 


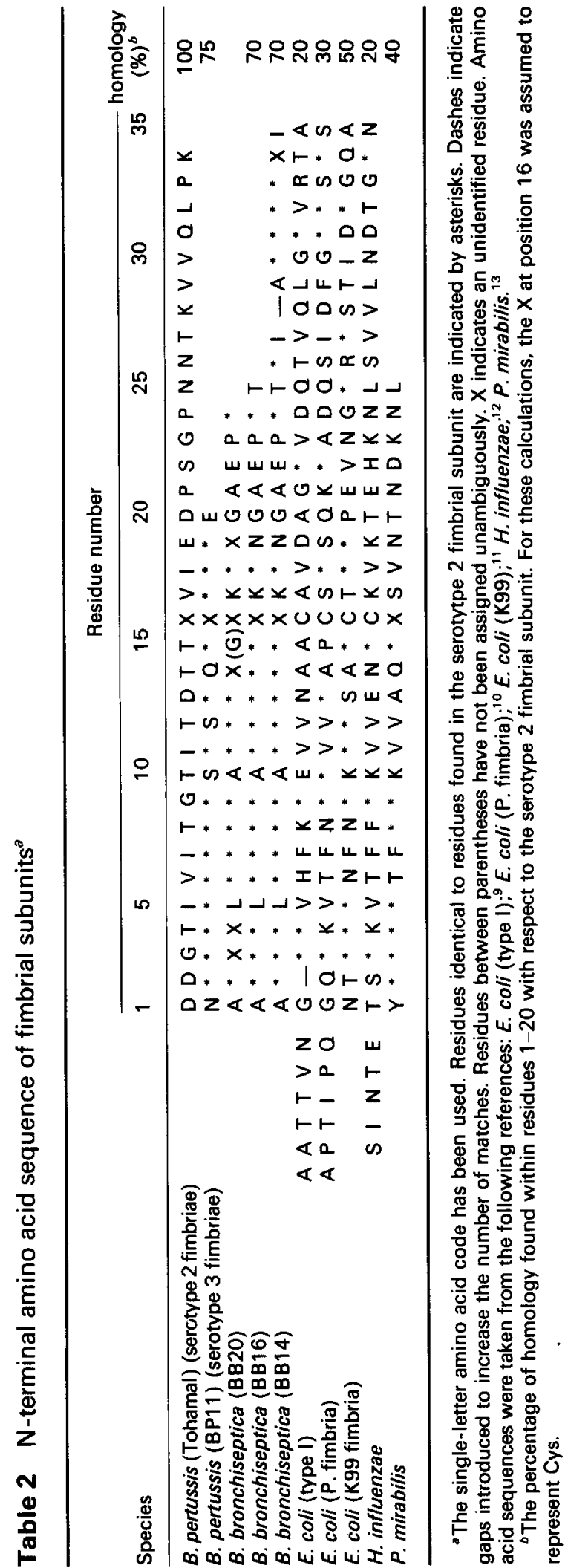


Table 3 Bacterial strains

\begin{tabular}{lll}
\hline \multicolumn{1}{c}{ Strains } & \multicolumn{1}{c}{$\begin{array}{c}\text { Strain } \\
\text { designation }\end{array}$} & \multicolumn{1}{c}{ Source/Reference } \\
\hline B. pertussis (2, 3) & Wellcome 28 & $(3)$ \\
B. pertussis (2) & Tohamal & $(20)$ \\
B. pertussis (2) & BP356 & $(21)$ \\
B. pertussis (2+/-, 3) & BP5 & $(22)$ \\
B. pertussis (2, 3) & BP6 & $(23)$ \\
B. pertussis (3) & BP11 & clinical isolate (human) \\
B. pertussis (3) & BP12 & clinical isolate (human) \\
B. pertussis (2) & BP17 & clinical isolate (human) \\
B. pertussis (2) & BP18 & clinical isolate (human) \\
B. bronchiseptica & BB14 & clinical isolate (pig) \\
B. bronchiseptica & BB15 & clinical isolate (pig) \\
B. bronchiseptica & BB16 & clinical isolate (pig) \\
B. bronchiseptica & BB19 & clinical isolate (dog) \\
B. bronchiseptica & BB20 & clinical isolate (dog) \\
B. bronchiseptica & BB26 & clinical isolate (dog) \\
B. avium & BA21 & (17) \\
B. avium & BA22 & (17) \\
B. parapertussis & BPP24 & clinical isolate (human) \\
B. parapertussis & BPP25 & clinical isolate (human) \\
\hline
\end{tabular}

\footnotetext{
${ }^{8}$ Numbers between parentheses designate serotype as determined by slide agglutination.

${ }^{b}$ Derived from Tohamal, contains a Tn5 insertion in the pertussis toxin genes.
}

$\mathrm{N}$-terminal amino acid sequence analyses revealed only five differences in the first 20 residues of the serotype 2 and 3 fimbrial subunits (Table 2). Only one difference (at position 15) was detected in the sequence of the three $B$. bronchiseptica polypeptides analyzed. A large degree of homology was also observed between the $B$. pertussis and $B$. bronchiseptica polypeptides, especially within the first 20 amino acid residues. These results clearly indicate that the three isolated $B$. bronchiseptica polypeptides represent fimbrial subunits, and substantiate our assumption that the serotype 2 and 3 antiserum can be used to identify fimbrial subunits in different Bordetella species.

For comparison, the $\mathrm{N}$-terminal amino acid sequences of fimbrial subunits derived from Escherichia coli, Haemophilus influenzae and Proteus mirabilis are included in Table 3. These fimbrial subunits all showed some resemblance in primary structure with the Bordetel/a subunits. An unidentified residue was observed at position 16 in all Bordetella fimbrial subunits. For several reasons we presume that this residue represent a cysteine. First, a cysteine is generally found at this position in other fimbrial subunits (Table 2). ${ }^{1}$ Second, DNA sequence analyses have confirmed the presence of a cysteine at position 16 in the serotype 2 fimbrial subunit (I. Livey, unpublished data).

\section{Identification of fimbrial genes in Bordetella species}

In order to isolate $B$. pertussis fimbrial genes by molecular cloning, a DNA probe was derived from the first ten amino-terminal residues of the serotype 2 fimbrial subunit (Fig. 2). Since most of these residues are conserved in the five Bordetella fimbrial subunits analyzed, we expected that the probe could be used to identify fimbrial subunit genes in several Bordetella species. To test this assumption, the probe was hybridized to genomic blots of Sall digested chromosomal DNA from $B$. pertussis, $B$. 


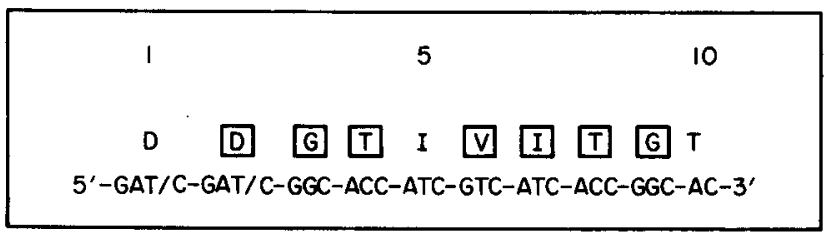

Fig. 2. Synthetic oligonucleotide probe derived from the $\mathrm{N}$-terminal amino acid sequence of the $B$. pertussis serotype 2 fimbrial subunit. The probe consists of a pool of four different oligonucleotides harboring either a $\mathrm{T}$ or a $\mathrm{C}$ at the wobble position of the first and second codon. The nucleotides at the remaining wobble positions were chosen on the basis of codon-usage in the pertussis toxin genes. ${ }^{14,15}$ The corresponding amino acid sequence of the serotype 2 fimbrial subunit is shown in the single-letter code. Amino acid residues, conserved in all Bordetella fimbrial subunits analyzed, have been blocked.

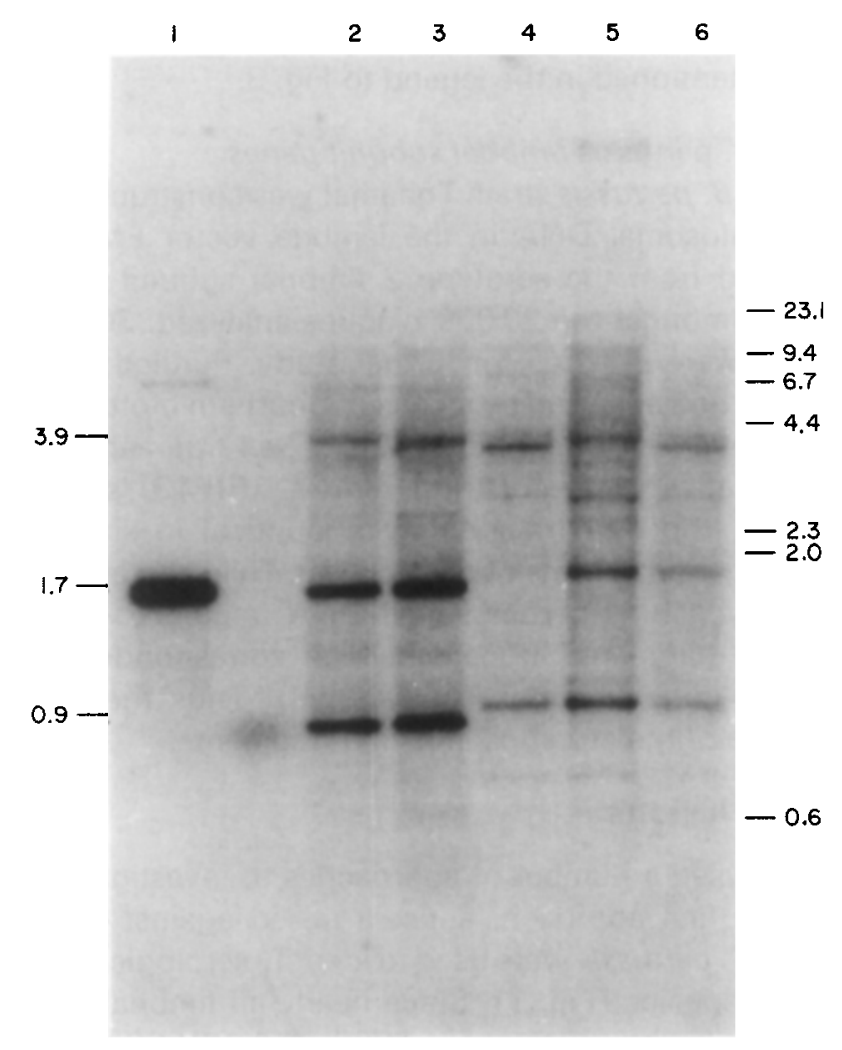

Fig. 3. Southern blots of Sa/l-digested DNA with the synthetic serotype 2 oligonucleotide probe. DNA was digested with $\mathrm{Sall}$, separated on a $0.8 \%$ agarose gel and subsequently transferred to a Gene-ScreenPlus membrane. The membrane was incubated with the ${ }^{32} \mathrm{P}$-labelled probe for $16 \mathrm{~h}$ at $51^{\circ} \mathrm{C}$. The membrane was washed for $15 \mathrm{~min}$ at $51^{\circ} \mathrm{C}$, and $10 \mathrm{~min}$ at $65^{\circ} \mathrm{C}$. Autoradiography was for three days with an intensifier screen. The numbers on the left and right indicate the sizes (in kbp) of Sa/l fragments detected in $B$. pertussis, and of marker DNA fragments, respectively. Lane 1, $\lambda$ RIP13 (see text); the remaining lanes contain chromosomal DNA derived from Bordetella strains: lane 2, B. pertussis (Tohamal); lane 3, B. pertussis (Wellcome 28); lane 4, B. parapertussis (BPP24); lane 5, B. bronchiseptica (BB26); lane 6, B. bronchiseptica (BB16).

bronchiseptica and B. parapertussis (Fig. 3). B. avium DNA was not analyzed, because it appeared to be refractory to cleavage by $S a l l$. The probe hybridized to three $S a / l$ fragments $(3.9,1.7$ and 0.9 kilobase pairs; $\mathrm{kbp})$ in the two $B$. pertussis strains tested, suggesting the presence of three fimbrial subunit genes. The two smaller Sa/l fragments hybridized more efficiently with the probe than the large fragment, suggesting a larger degree of homology with the $\mathrm{N}$-terminus of the serotype 2 gene. 
Five to six Sa/l fragments were detected in digests of DNA derived from $B$. bronchiseptica and $B$. parapertussis (Fig. 3). The Sall fragments detected in these two species of Bordetella were very similar or identical in size. In fact the pattern of bands observed with the $B$. bronchiseptica strain BB16 and the $B$. parapertussis strain was identical, except for the absence of a $1.9 \mathrm{kbp} \mathrm{Sall} \mathrm{fragment} \mathrm{in} B$. parapertussis. A small difference was also observed between the two $B$. bronchiseptica strains, in that one $3.9 \mathrm{kbp} \mathrm{Sall} \mathrm{fragment} \mathrm{was} \mathrm{detected} \mathrm{in} \mathrm{strain} \mathrm{BB26,} \mathrm{whereas} \mathrm{two} \mathrm{Sa/l} \mathrm{fragments}$ of similar size were detected in strain BB16.

To be able to include $B$. avium in our comparison, genomic blots were also made using the restriction enzyme BssHII, which cleaves DNA from all four Bordetella species well. The results (not shown) confirmed our experiments with Sall digested chromosomal DNA. Furthermore, no hybridization was observed with $B$. avium DNA, under the conditions mentioned in the legend to Fig. 3.

\section{Molecular cloning of $\mathrm{B}$. pertussis fimbrial subunit genes}

A genomic bank of the $B$. pertussis strain Tohamal was constructed by cloning partially Sau3A digested chromosomal DNA in the lambda vector EMBL3. ${ }^{16}$ The synthetic oligonucleotide derived from the serotype 2 fimbrial subunit (Fig. 2) was used to screen the bank, and amongst the 20000 plaques analyzed, 30 positive clones were found, nine of which were selected for further study. Purified DNA from the clones was digested with $S a / l$, and analyzed by means of Southern blotting using the synthetic probe. Five clones contained an identical $1.7 \mathrm{kbp} \mathrm{Sall} \mathrm{fragment} \mathrm{which} \mathrm{hybridized} \mathrm{to}$ the probe. A representative of one of these clones, $\lambda$ RIP13, is included in Fig. 3. It appeared that the $1.7 \mathrm{kbp} \mathrm{Sall} \mathrm{fragment} \mathrm{was} \mathrm{identical} \mathrm{in} \mathrm{size} \mathrm{to} \mathrm{one} \mathrm{of} \mathrm{the} S a / l$ fragments detected in genomic blots of $B$. pertussis. This indicates that the five clones contain an intact copy of this chromosomal DNA fragment. The remaining clones contained smaller Sall fragments, none of which corresponded to one of the Sa/l fragments detected in genomic blots (not shown). Thus these clones contain an incomplete copy of one of the chromosomal Sa/l fragments.

\section{Discussion and conclusions}

In this study we have used a number of approaches to investigate the fimbriae of the genus Bordetella. In a first approach, antisera raised against the serotype 2 and 3 fimbrial subunits from $B$. pertussis were used to identify serological related polypeptides in different Bordetella species (Fig. 1). Since nearly all fimbrial subunits analyzed to date have molecular weights between 14000 and $30000,{ }^{1}$ we were especially interested in polypeptides in this molecular weight range. Cross-reacting polypeptides falling into this category were observed in all four Bordete/la species investigated. In $B$. bronchiseptica strains four to six cross-reacting polypeptides were observed, suggesting that these strains produce a large number of different fimbrial subunits. This is also suggested by the work of Lee et al., ${ }^{7}$ which has revealed the presence of three different fimbrial subunits in $B$. bronchiseptica strains. Furthermore, these authors have also observed that $B$. bronchiseptica and $B$. pertussis fimbrial subunits are serologically related. It is noteworthy that the degree of serological relatedness between the two $B$. pertussis fimbrial subunits is smaller than between the $B$. pertussis and some $B$. bronchiseptica subunits. In $B$. parapertussis strains, one polypeptide serologically related to $B$. pertussis fimbriae was detected, whereas two to three of these polypeptides were found in $B$. avium strains. To our knowledge this is the first evidence for the occurrence of fimbriae in these species.

Our serological studies suggest that the four Bordetella species produce a group of 
related fimbrial subunits. Additional evidence for the relatedness between Bordetella fimbrial subunits was obtained from amino acid analyses and Southern blotting experiments. The two $B$. pertussis fimbrial subunits, and three serologically related $B$. bronchiseptica polypeptides were purified and their amino acid composition and $\mathrm{N}$ terminal amino acid sequence was determined. It appeared that these polypeptides were very similar in amino acid composition (Table 1). Furthermore, extensive homology was observed in their $\mathrm{N}$-terminal amino acid sequences (Table 2). Homology was also observed with fimbrial subunits from $E$. coli, $H$. influenzae and $P$. mirabilis. The highest degree of homology was observed with the $E$. coli $\mathrm{K} 99$ and $P$. mirabilis fimbrial subunits; 50 and $40 \%$ homology, respectively, with the first 20 amino acid residues of the $B$. pertussis serotype 2 fimbrial subunit. No significant homology was observed with fimbrial subunits from Neisseria strains (not shown).

In another approach to study the fimbriae of the genus Bordetella, we used a synthetic oligonucleotide probe (Fig. 2) to identify fimbrial genes in genomic blots (Fig. 3). Since the probe was derived from a region of the $B$. pertussis serotype 2 fimbrial subunit, which is well conserved in both $B$. pertussis and $B$. bronchiseptica, we expected that the probe could be used to identify fimbrial genes in different Bordetella species. The probe hybridized to $B$. pertussis, $B$. bronchiseptica and $B$. parapertussis DNA (Fig. 3), but not to $B$. avium DNA (not shown). In genomic blots of Sall digested DNA from $B$. pertussis, $B$. bronchiseptica and $B$. parapertussis three to five DNA fragments were detected, with very similar or identical molecular weights. These findings are consistent with taxonomic studies, ${ }^{17,18}$ which have shown that $B$. pertussis, $B$. bronchiseptica and $B$. parapertussis are very closely related and can be classified as a single species, whereas $B$. avium strains are genetically divergent enough to warrant specific status. Especially the genomic blots of $B$. bronchiseptica and $B$. parapertussis were very similar, confirming the close genetic relationship between some $B$. bronchiseptica strains and $B$. parapertussis. ${ }^{18}$ Interestingly, no difference was observed in the genomic blots of the $B$. pertussis strains Wellcome 28 and Tohamal, although the Wellcome 28 strain produces both the serotype 2 and 3 fimbrial subunits, ${ }^{3}$ while the Tohamal strain expresses the serotype 2 fimbrial subunit only (Fig. 1). This suggests that a silent copy of the serotype 3 fimbrial subunit gene is present in the Tohamal strain.

The five to six Sa/l fragments detected in genomic blots of $B$. bronchiseptica corresponded well to the number of cross-reacting polypeptides (four to six) found in these strains with immunoblotting. Such a correlation was not observed for the $B$. parapertussis and $B$. pertussis strains analyzed. In $B$. parapertussis five Sall fragments were detected with the probe, while only one polypeptide was observed in immunoblots. In $B$. pertussis three Sall fragments hybridized to the DNA probe, while only two types of fimbriae have been described in this species. The latter discrepancy is especially significant, because the fimbriae of $B$. pertussis have been studied intensively. ${ }^{5,6,8}$ The discrepancy between the genomic blots and immunoblots might be due to the fact that some fimbrial subunits are not recognized by the antisera used. It is also possible that some genes are not expressed, or only at a very low level. In this context it should be noted that several fimbriae have been shown to be heteropolymers consisting of a major subunit and one or more minor subunits. ${ }^{119}$ The minor fimbrial subunits have generally eluded biochemical and serological detection, and evidence for their existence was first based on genetic grounds. In some cases these minor components have been shown to contain the receptor-binding domain. ${ }^{19}$ It is tempting to speculate that the tentative third fimbrial subunit gene detected in $B$. pertussis codes for such a minor subunit.

The presence of multiple fimbrial genes in Bordetella strains might be explained in 
several ways. It is possible that these genes code for antigenic variants which allow the pathogen to escape from immune surveillance. Another possibility is that these genes code for subunits which differ not only in structure but also in function. As a first step to address these questions, we have started to isolate the three $B$. pertussis fimbrial genes by molecular cloning. The DNA probe derived from the serotype 2 fimbrial subunit was used to identify fimbrial genes in a genomic bank of the $B$. pertussis strain Tohamal. A number of clones were identified which contain a $1.7 \mathrm{kbp}$ Sa/l fragment also observed in genomic blots (Fig. 3). A similar DNA fragment has been cloned from the $B$. pertussis strain Wellcome 28, and DNA sequence analyses has revealed that this fragment contains the serotype 2 fimbrial subunit gene (I. Livey, unpublished data). We are currently characterizing the remaining two $B$. pertussis fimbrial genes.

\section{Materials and methods}

Strains and culture conditions. The Bordetella strains used in this study are listed in Table 1. Strains were maintained in milk containing $30 \%$ glycerol at $-70^{\circ} \mathrm{C}$, and reconstituted by growth on Bordet-Gengou agar plates. ${ }^{24}$ Haemolytic colonies from the Bordet-Gengou agar plates were used to inoculate a modified Cohen-Wheeler medium, designated Verwey medium. ${ }^{25}$ Growth was carried out with shaking at 35 to $37^{\circ} \mathrm{C}$, for 2 to 3 days. Strain BP356 was grown in the presence of $25 \mu \mathrm{g} / \mathrm{ml}$ kanamycin.

Isolation of fimbriae. For the isolation of fimbriae, B. bronchiseptica strains were grown in Brain Heart Infusion (Difco Laboratories, Detroit, Mich), whereas $B$. pertussis strains were grown in Verwey medium. Haemolytic colonies from Bordet-Gengou plates were used to inoculate $400 \mathrm{ml}$ of liquid medium. After growth for one or two days at 35 to $37^{\circ} \mathrm{C}$, this culture was used to inoculate $4 \mathrm{I}$ of liquid medium and growth was continued until the culture reached an absorbance at $650 \mathrm{~nm}$ of 2.0. Subsequently, cells were harvested and suspended in PBS (0.01 M sodium phosphate, $\mathrm{pH} 7.4,0.155 \mathrm{M} \mathrm{NaCl})$, supplemented with $4 \mathrm{M}$ urea, to an absorbance at $650 \mathrm{~nm}$ of 60 . Fimbriae were detached from the cells by heating this suspension at $60^{\circ} \mathrm{C}$ for $30 \mathrm{~min}$. Unless otherwise stated, all subsequent steps were carried out at 0 to $4^{\circ} \mathrm{C}$. Cells were pelleted by centrifugation for $20 \mathrm{~min}$ at $20000 \mathrm{~g}$. Membrane fragments were removed from the supernatant in a second centrifugation step $(90 \mathrm{~min}$ at $175000 \mathrm{~g}$ ). Fimbriae were precipitated from the supernatant with $0.5 \mathrm{M} \mathrm{NaCl}$ and $4 \%$ (wt/vol) polyethyleneglycol 6000 . After incubating for $16 \mathrm{~h}$ at $4^{\circ} \mathrm{C}$, fimbriae were collected by centrifugation (60 min at 20000 g), the pellet was dissolved in $0.05 \mathrm{M}$ Tris $\mathrm{HCl} \mathrm{pH} 7$ with $4 \mathrm{M}$ urea, and dialyzed against the same buffer. At this stage, the presence of fimbriae was verified by means of electron microscopy. Undissolved protein was removed by centrifugation $(20 \mathrm{~min}$ at $20000 \mathrm{~g}$ ), and the fimbriae suspension was stored at $-20^{\circ} \mathrm{C}$. For some preparations it was necessary to include an additional purification step. Fimbriae were suspended in $0.05 \mathrm{M}$ Tris $\mathrm{HCl} \mathrm{pH} 8$ with $4 \mathrm{M}$ urea and $0.1 \%$ SDS, and this suspension was heated at $60^{\circ} \mathrm{C}$ for $20 \mathrm{~min}$. Under these conditions most contaminants dissociate into smaller subunits, whereas the fimbriae maintain their macromolecular structure. Fimbriae were collected by centrifugation $\left(8 \mathrm{~h}\right.$ at $175000 \mathrm{~g}$ and $8^{\circ} \mathrm{C}$ ), suspended in $0.05 \mathrm{M}$ Tris $\mathrm{HCl} \mathrm{pH} 8$ with $4 \mathrm{M}$ urea, and stored at $-20^{\circ} \mathrm{C}$. At this stage, $B$. bronchiseptica preparations still contained a number of different polypeptide species, presumably representing different fimbrial subunits. Therefore, in a final purification step, a single polypeptide species was isolated by means of preparative SDS-polyacrylamide gel electrophoresis followed by electroelution from the gel.

Preparation of antisera against fimbrial subunits. Serotype 2 and 3 fimbriae were isolated from the $B$. pertussis strains Tohamal and BP13, respectively, as described above. Subsequently, approximately $1 \mathrm{mg}$ of fimbrial protein was electrophorized in a 14\% SDS-polyacrylamide gel. The fimbrial subunit band was detected by staining in Coomassie blue in water, cut from the gel and emulsified in PBS $(0.01 \mathrm{M}$ sodium phosphate $\mathrm{pH} 7.4$ and $0.155 \mathrm{M} \mathrm{NaCl})$. Before immunization, the emulsion was mixed 1:1 with Freund's complete or incomplete adjuvant. Rabbits were immunized subcutaneously with $0.25 \mathrm{mg}$ of fimbrial protein in Freund's complete adjuvant. After 21 and 28 days, boosters were given subcutaneously consisting of $0.25 \mathrm{mg}$ of fimbrial protein in Freund's incomplete adjuvant. At day 38 the rabbits were bled. 
SDS-polyacrylamide gel electrophoresis. SDS-polyacrylamide gel electrophoresis was performed in 12 or $14 \%$ acrylamide containing gels, essentially as described by Laemli. ${ }^{26}$

\section{Immunoblotting. Immunoblotting was basically done as described by van Embden et al. ${ }^{27}$}

Protein determination. Protein concentration was determined with a BioRad Protein Assay kit (Bio-Rad, Richmond, California).

DNA techniques. Chromosomal DNA was prepared as described by van Embden et al. ${ }^{27}$ Southern blotting was performed as previously described. ${ }^{28}$ Prehybridization and hybridization was performed in $5 x$ SSPE ( $1 x$ SSPE $=0.01 \mathrm{M}$ sodium phosphate $\mathrm{pH} 7.0,0.18 \mathrm{M} \mathrm{NaCl}$, and $0.001 \mathrm{M}$ EDTA) containing $1 \%$ SDS, $5 \times$ Denhardt's solution, ${ }^{29}$ and $50 \mu \mathrm{g} / \mathrm{ml}$ Herring sperm DNA. Washings were performed in $5 x$ SSPE containing $0.1 \%$ SDS.

A genomic bank of the $B$. pertussis strain Tohamal was constructed as follows. Tohamal DNA was parially cleaved with Sau3A, and fragments having sizes between 10 and 20 kilobase pairs $(\mathrm{kbp})$ were isolated by preparative gel electrophoresis in $0.8 \%$ agarose. The fragments were ligated with $B a m \mathrm{HI}$ cleaved EMBL3 DNA, ${ }^{16}$ and after in vitro packaging and transduction into the $E$. coli K12 strain LE392, ${ }^{16}$ about 120000 independent clones were obtained. The genomic bank was screened for fimbrial genes with an oligonucleotide probe using GeneScreen-Plus (Du Pont, Boston, Massachusetts), according to the instructions provided by the manufacturer. Manipulation of lambda recombinants was performed following the protocols of Maniatis et al..$^{30}$

Amino acid analyses. Amino acid analyses were performed on a Waters HPLC equipment, with post-column derivatization by o-phthaldialdehyde. Glucose-amine appears as a broad peak after phenylalanine. Hydrolysis was performed in $6 \mathrm{M} \mathrm{HCl}$ at $108^{\circ} \mathrm{C}$ for $20 \mathrm{hrs}$. Amino acid sequences were determined on a gas-phase sequencer (model $470 \mathrm{~A}$, Applied Biosystems) using program $02 \mathrm{~N}$ RUN. PTH-amino acid derivatives generated by the sequence were analyzed by HPLC (Waters) at 254 and $313 \mathrm{~nm}$ on a $4.6 \times 125 \mathrm{~mm}$ Spherisorb S5-ODS column.

We are indebted to Tineke Olij for secretarial assistance, Anja Hamers for preparing $B$. bronchiseptica chromosomal DNA, Bert Verhey and Diana Ruyzendaal for synthesizing the oligonucleotide probe, and to Dick van Brenk, Wim Sandman and Jaap Valkenburg for serotyping.

\section{References}

1. De Graaf FK, Mooi FR. The fimbrial adhesins of Escherichia coli. In: Rose AH, Tempest DW, eds. Advances in Microbial Physiology 1986; 28: 65-143.

2. Morgan RI, Isaacson RE, Moon HW, Brinton CC, To CC. Immunization of suckling pigs against enterotoxigenic Escherichia coli induced diarrheal disease by vaccinating dams with purified 987 or K99 pili: protection correlates with pilus homology of vaccine and challenge. Infect Immun 1978; 22: 771-7.

3. Robinson A, Ashworth LAE, Baskerville A, Irons LI. Protection against intranasal infection of mice with Bordetella pertussis. Proceedings of the Fourth International Symposium on Pertussis. Dev Biol Stand 1984; 61: 165-72.

4. Orskov I, Orskov F. Serology of Escherichia coli fimbriae. Prog Allergy 1983; 33: 80-105.

5. Ashworth LAE, Irons I, Dowsett AB. Antigenic relationship between serotype-specific agglutinogen and fimbriae of Bordetella pertussis. Infect Immun 1982; 37: 1278-81.

6 Irons LI, Ashworth LAE, Robinson A. Release and purification of fimbriae from Bordetella pertussis. Proceedings of the Fourth International Symposium on Pertussis. Dev Biol Stand 1984; 61: $153-63$.

7. Lee SW, Way AW, Osen EG. Purification and subunit heterogeneity of pili from Bordete/la bronchiseptica. Infect immun 1986; 51: 586-93.

8. Zhang JM, Cowell JL, Steven AC, Carter PH, McGrath PP, Manclark CR. Purification and characterization of fimbriae isolated from $B$. pertussis. Infect Immun 1985; 48: 422-7.

9. Klemm P. The fimA gene encoding the type I fimbrial subunit of Escherichia coli: nucleotide sequence and primary structure of the protein. Eur J Biochem 1984; 143: 395-9.

10. Baga M, Normark S, Hardy J, O'Hanley P, Lark D, Olsson O, Schoolnik G, Falkow S. Nucleotide sequence of the papA gene encoding the pap pilus subunit of human uropathogenic Escherichia coli. $J$ Bacteriol 1984; 157: 330-3.

11. Roosendaal B, Gaastra W, De Graaf FK. The nucleotide sequence of the gene encoding the K99 subunit of enterotoxigenic Escherichia coli. FEMS Microbiol Lett 1984; 22: 253-8. 
12. Guerina NG, Langermann S, Schoolnik GK, Kessler TW, Goldmann DA. Purification and characterization of Haemophilus influenzae pili, and their structural and serological relatedness to Escherichia coli $\mathrm{P}$ and mannose-sensitive pili. J Exp Med 1985; 161: 145-59.

13. Wray SK, Hull SI, Cook RG, Barrish J, Hull RA. Identification and characterization of a uroepithelial cell adhesin from a uropathogenic isolate of Proteus mirabilis. Infect Immun 1986; 54: 43-9.

14. Locht C, Keith JM. Pertussis toxin gene: neucleotide sequence and genetic organization. Science 1986; 232: 1258-64.

15. Nicosia A, Perugini M, Franchini C, Casagli MC, Borri MG, Antoni G, Almoni M, Neri P, Ratti G, Rappuoli R. Cloning and sequencing of the pertussis toxin genes: Operon structure and gene duplication. Proc Natl Acad Sci USA 1986; 83: 4631-5.

16. Karn J, Brenner $S$, Barnett $L$. New bacteriophage lambda vectors with positive selection for cloned inserts. In: Wu R, Grossman L, Moldave K, eds. Methods in Enzymology: Recombinant DNA. New York: Academic Press 1983; 101: 3-19.

17. Kersters K, Hinz K, Hertle A, Segers P, Lievers A, Siegman O, De Ley J. Bordetella avium sp. nov., isolated from the respiratory tract of turkeys and other birds. Int $J$ System Bacteriol 1984; 34: 56-70.

18. Musser M, Hewlett EL, Peppler MS, Sclander RK. Genetic diversity and relationships in population of Bordetella spp. J Bacteriol 1986; 166: 230-7.

19. Uhlin BE, Baga $M$, Göransson $M$, Lindberg FP, Lund $B$, Norgren $M$, Normark $S$. Genes determining adhesin formation in uropathogenic Escherichia coli. In: Goebel W, ed. Current Topics in Microbiology and Immunology: Genetic Approaches to Microbial Pathogenicity. Berlin: Springer-Verlag, 1985; 118 : 163-78.

20. Sato $\mathrm{Y}$, Arai H. Leukocytosis-promoting factor of Bordete/la pertussis. I. Purification and characterization. Infect Immun 1972; 6: 899-904.

21. Weiss AA, Hewlett EL, Myers GA, Falkow S. Tn5-induced mutations affecting virulence factors of Bordetella pertussis. Infect Immun 1983; 42: 33-41.

22. Pillemer L. Adsorption of protective antigen of Haemophilus pertussis on human red cell stomata. Proc Soc Exp Biol Med 1950; 75: 704-5.

23. Cohen HH, Lettink GJ. Selection of Haemophilus pertussis strains for vaccine production in the mouse protection test in a balanced design. J Immunol 1956; 77: 299-304.

24. Kendrick PL, Eldering G, Bradford WL. Whooping cough. In: Bodily HL, Updyke EL, Mason JO, eds. Diagnostic Procedures for Bacterial, Mycotic, and Parasitic Infections, 5 th edn. New York: American Public Health Association, 1970: 106-17.

25. Verwey WF, Thiele EH, Sage DN, Schuchardt LT. A simplified liquid culture medium for the growth of Haemophilus pertussis. J Bacteriol 1949; 50: 127-34.

26. Laemli UK. Cleavage of structural proteins during the assembly of the head of bacteriophage T4. Nature (Lond.) 1970; 227: 680-5.

27. Van Embden JDA, van der Donk HJ, van Eijk RV, van der Heide $H G$, de Jong JA, van Olderen $M F$, Osterhaus AD, Schouls LM. Molecular cloning and expression of Treponema pallidum DNA in Escherichia coli K12. Infect Immun 1983; 42: 187-96.

28. Reed KC, Mann DA. Rapid transfer of DNA from agarose gels to nylon membranes. Nucl Acids Res 1985; $13: 7207-21$.

29. Denhardt DT. A membrane-filter technique for the detection of complementary DNA. Biochem Biophys Res Commun 1966; 23: 641-6.

30. Maniatis T, Fritsch EF, Sambrook J. Molecular cloning. A laboratory manual. Cold Spring Harbor Laboratory. 1982 